\title{
BMJ Open Psychological and occupational impact of the COVID-19 pandemic on UK surgeons: a qualitative investigation
}

\author{
Tmam Abdulaziz Al-Ghunaim (D) , ${ }^{1}$ Judith Johnson, ${ }^{1}$ Chandra Shekhar Biyani, ${ }^{2}$ \\ Daryl O'Connor (1D ${ }^{1}$
}

To cite: Al-Ghunaim TA, Johnson J, Biyani CS, et al. Psychological and occupational impact of the COVID-19 pandemic on UK surgeons: a qualitative investigation. BMJ Open 2021:11:e045699. doi:10.1136/ bmjopen-2020-045699

- Prepublication history and additional material for this paper is available online. To view these files, please visit the journal online (http://dx.doi.org/10. 1136/bmjopen-2020-045699)

Received 11 October 2020 Revised 02 March 2021 Accepted 22 March 2021

Check for updates

(c) Author(s) (or their employer(s)) 2021. Re-use permitted under CC BY-NC. No commercial re-use. See rights and permissions. Published by BMJ.

${ }^{1}$ School of Psychology, University of Leeds, Leeds, UK

${ }^{2}$ Department of Urology, St James's University Hospital Hepatobiliary, Leeds, UK

Correspondence to Tmam Abdulaziz Al-Ghunaim; t.alghunaim@leeds.ac.uk

\section{ABSTRACT}

Background The COVID-19 pandemic represents the greatest biopsychosocial emergency the world has faced for a century. The pandemic has changed how individuals live and work, and in particular, frontline healthcare professionals have been exposed to alarming levels of stress.

Objective The aim of this study was to understand the professional and personal effects of COVID-19 pandemic on surgeons working in the UK National Health Service (NHS).

Setting Surgical departments in the NHS.

Design Between May and July 2020, as part of an ongoing study, we asked surgeons two open-ended questions: 'What challenges are the COVID-19 crisis currently presenting to you in your work and home life?' and 'How is this stress affecting you personally?' Thematic analysis was used for the qualitative data. Responses to the second question were also categorised into four groups reflecting valence: positive, neutral, mildly negative and strongly negative.

Results A total of 141 surgeons responded to the survey and the results indicated that $85.8 \%$ reported that they were generally negatively affected by the COVID- 19 pandemic, of which $7.8 \%$ were strongly affected in a negative way. Qualitative thematic analysis identified four key themes from responses relating to the impact of the pandemic: (1) changing and challenging work environment as a result of COVID-19; (2) challenges to professional life and development; (3) management of change and loss in the respondents' personal lives; (4) emotional and psychological impacts.

Conclusion The results highlighted the substantial emotional and psychological effects of the COVID-19 pandemic on surgeons' mental health, particularly in relation to fear and anxiety, loss of motivation, low mood, stress and burnout. There is an urgent need for workplace support and mental health interventions to help surgeons cope with the difficulties they face during the ongoing COVID-19 pandemic.

\section{INTRODUCTION}

In December 2019, a novel coronavirus later named 'severe acute respiratory syndrome coronavirus 2' (SARS-CoV-2) was first reported as the cause of an outbreak of respiratory illness in Wuhan City, China.

\section{Strengths and limitations of this study}

This study included surgeons with different specialities, grades (core surgical trainees to consultants), qualifications and regions to give broad insight into the psychological and occupational impact of the COVID-19 pandemic on UK surgeons.

- Two authors worked independently to code the data regarding the valence of the impact of the pandemic on surgeons, minimising subjective coding bias.

- We were not able to monitor our response rate, and as such, it is not possible to know whether our sample reflected the wider population of UK surgeons from which it was recruited.

- The study relied on surgeons' self-report of their own experiences and mental well-being.

The WHO labelled the disease caused by this virus COVID-19, short for coronavirus disease 2019. On 30 January 2020, the WHO announced that cases had been confirmed worldwide. ${ }^{2}$

The seriousness, scale and virulence of COVID-19 have had a major negative impact on people's mental health. ${ }^{3}$ This is evident as many individuals are struggling to cope with the pandemic. A recent study has shown that the mental health and well-being of the UK adult population appears to have been substantially affected in the initial phase of the COVID-19 pandemic, especially for women, young adults, the socially disadvantaged and those with pre-existing mental health problems. ${ }^{4}$ In addition, the widespread outbreaks of infectious diseases, such as COVID-19, have been reported to cause public panic and mental illness. ${ }^{5}$ In a novel study by $\mathrm{Li} e t$ $a l$, the psychological impact of the COVID-19 pandemic on individuals' mental health was investigated by analysing the word frequencies, scores of emotional indicators that include anxiety and depression, and cognitive indicators such as social risk judgement and life satisfaction from 17865 Weibo users 
before and after the WHO announcement. The study found an increase in indicators of negative emotional and psychological outcomes (including depression, anxiety and anger) after the start of the pandemic. ${ }^{6}$ Furthermore, a study by Wang et al that focused on frontline healthcare professionals in Wuhan during the pandemic crisis reported health professionals suffering from acute stress disorder, along with an increased prevalence of anxiety and depression. This study also observed a strong link between COVID-19 pandemic and emotional distress such as depressive symptoms and anxiety, acute stress disorder and psychosomatic symptoms (such as chest pain). ${ }^{7}$

In the UK National Health Service (NHS), frontline healthcare workers are likely to be particularly vulnerable to mental health issues as a result of COVID-19 outbreak. Their work environment has changed dramatically, and they have been exposed to alarming levels of stress. For instance, many NHS doctors have been required to practise outside their defined areas of expertise, and cancellations of planned surgeries have reduced training opportunities. $^{8-11}$ A study that focused on the mental health of NHS workers during the COVID-19 pandemic found that healthcare workers experienced mild depression and increased levels of stress and anxiety. ${ }^{12}$

The lack of personal protective equipment (PPE) is another significant challenge that frontline healthcare professionals have faced in their work environment, one that has put NHS workers at increased risk. ${ }^{12}$ Jessop $e t a l^{13}$ found that the lack of PPE has negatively affected the mental health of healthcare staff. Moreover, recent research has suggested that NHS workers during COVID-19 pandemic experienced 'moral injury', which is defined as the psychological distress that induces a person to have negative thoughts about themselves or others. ${ }^{14}$

A current rapid review and meta-analysis by Kisely et $a l,{ }^{15}$ which sought to investigate the psychological effects of any emerging virus outbreak on healthcare workers, found that the staff who are in direct contact with infected patients were more susceptible to experience high levels of acute or post-traumatic stress and psychological distress. Moreover, being lower in the staff hierarchy, or parent with dependent children, or having a vulnerable or sick family member were also determined to be contributing risk factors for facing psychological distress. This review also ascertained that discrimination, disgust, stigma and lack of moral support for healthcare workers may also contribute to high levels of distress.

According to Gerada and Jones, ${ }^{16}$ among healthcare workers, surgeons are the most reluctant to seek support for mental health issues in spite of the symptoms they experience, including burnout and depression. Their unwillingness is closely related to concerns about losing their credibility as doctors and the stigma about seeking help within the medical community. Furthermore, a study by Upton $e t a l^{17}$ reported a concerningly high rate of burnout across various surgical specialties in the UK. Their study, which surveyed 1971 surgeons from 127 NHS hospital trusts, found that one-third of the respondents showed high levels of burnout or exhaustion. ${ }^{17}$

However, to the best of our knowledge, there has been no study on how surgeons have been affected by the current pandemic. Research is therefore urgently required concerning how the COVID-19 pandemic is affecting the mental health of surgeons to gain a clearer understanding in order to help inform future interventions and support plans. ${ }^{3}$ Therefore, the current study aimed to ask surgeons directly about the impact of the COVID-19 crisis on their work and home life.

\section{METHODS}

\section{Study design and participants}

This qualitative study is part of a larger longitudinal online survey investigating surgeon burnout. The larger study included a quantitative survey and a qualitative component, with the quantitative survey focusing on surgeon burnout and general patient care. By contrast, the qualitative component reported in the current paper assessed the impact of the COVID-19 outbreak on surgeons by offering two open-ended questions via the Qualtrics survey tool: "What challenges is the COVID-19 crisis currently presenting to you in your work and home life?' and 'How is this stress affecting you personally?'

All UK surgeons could participate in the survey, regardless of their specialty or status as trainees or consultants. Anyone outside of these groups were excluded, including retirees. Recruitment to the online survey was conducted between 5 May and 30 June 2020. Participants were enrolled using convenience and snowball sampling methods. Surgeons and surgical trainees working in various surgical specialties across the UK were invited to participate in the survey using social media channels (eg, Twitter) and 306 individual surgeons were approached using an available networking email list. The first invitation was sent, then a reminder was sent 5 days later. Twitter advertising consisted of 10 tweets published at various times with the hashtags 'surgeons, UK', 'NHS' and 'COVID-19'. The most recent UK surgeon statistics shows 57500 surgeons with various specialties. ${ }^{18}$ However, due to recruiting via Twitter, we were not able to monitor the response rate of participants. In total, 141 participants took part. Recruitment ceased once it was deemed by the authors that the qualitative data collected provided sufficient 'information power' to address the research questions. ${ }^{19}$

All participants were provided with information about the research, and their participation was voluntary.

\section{Patient and public involvement}

The development of the questionnaire and the choice of measures used were discussed with surgeons at a training event and feedback was received.

\section{Data analysis}

Data were screened and checked to confirm no participants had matching demographics (eg, matching age, 
gender, location and role), preventing multiple entries from single participants.

The data analysis covered qualitative (thematic) and descriptive analysis. Thematic analysis is considered a method that outperforms other methods due to its theoretical flexibility and ability to generate unanticipated insights by providing a detailed account of the data. ${ }^{20}$ The analysis framework developed by Braun and Clarke ${ }^{20}$ includes data familiarisation, initial code generation, theme searching, reviewing, defining and naming, and report production. This method was chosen to highlight similarities and differences across the dataset while generating unanticipated insights into the psychological and occupational effects of COVID-19 pandemic on surgeons. Responses to the first and second questions of the survey were analysed together using thematic analysis. ${ }^{20}$

The second question, 'How is this stress affecting you personally?' was also analysed following the approach of Taylor et al, ${ }^{21}$ which classified the content nature into four categories: positive, neutral, mildly negative and strongly negative. This allowed us to quantify the percentage of surgeons who felt the pandemic was affecting them negatively. For example, responses such as 'fatalistically' and 'the stress is significantly affecting me badly' were rated as strongly negative; 'not too badly' and 'mild' were deemed mildly negative; 'I have achieved a better worklife balance' was considered positive; and 'not affected', 'able to cope' and 'unsure' were categorised as neutral. Two authors (TAAG) who is $\mathrm{PhD}$ candidate of psychology and (DOC) who is professor of psychology worked independently to analyse the data, minimising subjective coding bias. Any disagreements were resolved by discussion. Inter-rater agreement between coders was good, resulting in a Kappa of 0.91 .

\section{RESULTS}

\section{Sample characteristics}

A total of 141 surgeons completed the survey (31 female, 91 male, 1 other and 18 did not disclose). Of these, 80 $(57 \%)$ were consultants, $37(26.5 \%)$ were specialty trainees, $13(9 \%)$ were core surgical trainees, $9(6.2 \%)$ were others including $2(1.3 \%)$ surgeons did not respond to this question.

Seventy-five $(53 \%)$ participants were from Urology followed by General Surgery $14(10 \%)$, then $10(7 \%)$ from Trauma and Orthopaedics, $8(6 \%)$ from Neurosurgery, 8 (6\%) for Oral and Maxillofacial, 6 (4\%) from Gynaecology, 4 (3\%) from Obstetrics and Gynaecology, 4 (3\%) from Vascular Surgery, 2 (1\%) from Plastic Surgery, 2 (1\%) from Colorectal, whereas the rest $(5,3.5 \%)$ from different specialties which include Hepatobiliary and Transplant Surgery, Oesophagus and Gastric, Ophthalmology, Otorhinolaryngology and Transplant and hepatobiliary surgery, 1 each. While three participants did not answer the question (2\%). The average age of the participants was 42.2 years (range $26-66$ years, SD 10.45). The average number of years practising as a surgeon was 14 years (range $1-37$ years, SD 9.7).

The survey found that 121 surgeons $(85.8 \%)$ reported being negatively affected by the COVID-19 pandemic, of these $11(7.8 \%)$ experienced a strongly negative effect and $110(78 \%)$ described mildly negative impact. In contrast, $8(12.7 \%)$ participants reported a neutral impact of the pandemic, and $2(1.5 \%)$ of the respondents stated a positive effect of the COVID-19 pandemic.

\section{Thematic analysis}

The thematic analysis identified four themes. The first theme references changing and challenging work environment as a result of the COVID-19 pandemic; the second theme identifies challenges to professional life and development; the third theme recognises managing change and loss in the respondents' personal lives; and the fourth theme highlights emotional and psychological impacts (table 1). All quotes are provided in the online supplemental file.

\section{Theme one: changing and challenging work environment}

This theme deals with how most hospitals during COVID-19 crisis have changed their structure, shifts, administration, staffing for COVID-19 cases, operational changes and so on. These responses detail how COVID-19 pandemic has had an impact on the work environment of surgeons.

\section{Dealing with constant change.}

These subthemes explain how surgeons cope with constant change through limited capacity for operative surgery and change of work structure.

- Limited capacity and operative surgery. This subtheme includes restricted capacity and minimal surgical operations as a result of the COVID-19 pandemic. Two surgeons mentioned the changes of the work environment in terms of limited capacity: 'reduced capacity'; 'At work ... limited capacity'. Furthermore, many comments mentioned capacity specifically in the context of operative surgery (eg, 'Reduced capacity for operative surgery').

- Change in work structure. Alteration in work structure involves surgeons changing roles, performing work in different ways or modifying work plans. There are many comments about working with unfamiliar environments (eg, 'changing pattern of work and on call'). The other comments mentioned this change by using a new method to communicate with patients by telephone: 'New methods of working-including telephone clinics'.

Some comments mentioned reallocated workers performing work they are unfamiliar with (eg, 'challenge of being asked to contribute to areas that I have not done for years under the pretext that it is covering COVID-19'). Other comments mentioned the changes arising from bad planning by management, such as 'Lack of leadership' and 'unrealistic planning by the management'. Also, some statements 
Table 1 Themes, descriptions, subthemes, example

\begin{tabular}{|c|c|c|c|}
\hline Themes & Descriptions & Subthemes & Example \\
\hline $\begin{array}{l}\text { Changing and challenging } \\
\text { work environment }\end{array}$ & $\begin{array}{l}\text { Most hospitals during } \\
\text { COVID-19 have changed } \\
\text { their structure, including } \\
\text { shifts, administrative staffing } \\
\text { for COVID-19 cases, } \\
\text { operational changes and so } \\
\text { on. These responses detail } \\
\text { how COVID-19 has affected } \\
\text { the work environment of } \\
\text { surgeons. }\end{array}$ & $\begin{array}{l}\text { (1) Dealing with constant } \\
\text { change } \\
\text { Limited capacity } \\
\text { Change in work structure } \\
\text { (2) Increased workload and } \\
\text { lack of work-life balance } \\
\text { (3) Surgeons struggling } \\
\text { with personal protective } \\
\text { equipment (PPE) }\end{array}$ & $\begin{array}{l}\text { 'Reduced capacity for operative } \\
\text { surgery' } \\
\text { 'Changing pattern of work and on } \\
\text { call' } \\
\text { 'Increased work load' } \\
\text { 'Lack of PPE' } \\
\text { 'PPE makes it difficult for patients } \\
\text { to hear you and see your non- } \\
\text { verbal response' }\end{array}$ \\
\hline $\begin{array}{l}\text { Challenges to professional life } \\
\text { and development }\end{array}$ & $\begin{array}{l}\text { This theme describes how } \\
\text { COVID-19 has affected } \\
\text { surgeons' performance at } \\
\text { work and their experience of } \\
\text { professional development. }\end{array}$ & $\begin{array}{l}\text { (1) Impact on surgeon's } \\
\text { performance } \\
\text { Difficult to make decisions } \\
\text { Less productive/work } \\
\text { slow } \\
\text { Tired } \\
\text { (2) Impact on surgeon's } \\
\text { development }\end{array}$ & $\begin{array}{l}\text { 'It is intellectually tiring to make } \\
\text { decisions' } \\
\text { 'Not being able to do my job } \\
\text { adequately' } \\
\text { 'Make me feel tired' } \\
\text { 'Zero access to any training, } \\
\text { either in theatre or clinic' }\end{array}$ \\
\hline $\begin{array}{l}\text { Management of change and } \\
\text { loss in personal lives }\end{array}$ & $\begin{array}{l}\text { This theme describes the } \\
\text { effects of COVID-19 on } \\
\text { surgeons' lives outside work }\end{array}$ & $\begin{array}{l}\text { (1) Childcare issues } \\
\text { (2) Family life/relationship } \\
\text { (3) Having to cancel } \\
\text { honeymoons/ weddings } \\
\text { (4) Reduced leisure } \\
\text { opportunities } \\
\text { (5) Poor sleep }\end{array}$ & $\begin{array}{l}\text { 'Children off school-childcare } \\
\text { challenges because both of us are } \\
\text { key workers and school provision } \\
\text { does not have options before and } \\
\text { after school care' } \\
\text { 'Loss of communication with wife' } \\
\text { 'Wedding, honeymoon and annual } \\
\text { leave cancelled' } \\
\text { 'Travel. The pub is shut and I can't } \\
\text { go on holiday' } \\
\text { 'Some sleeplessness' }\end{array}$ \\
\hline
\end{tabular}

relate to working from home (eg, 'I have had to work from home due to immunosuppressive medication.') By contrast, some respondents see this change as positive, as it makes the work easier (eg, 'opportunity for more home working would be beneficial').

\section{Workload and lack of work-life balance.}

An increased workload and a lack of work-life balance are challenges that surgeons face in the work environment during the COVID-19 pandemic. Many comments mentioned an increased workload (eg, 'overworking' and 'workload post pandemic'). However, many surgeons also mentioned how this workload affects their work-life balance (eg, 'Working more weekends. Different shift pattern than my partner so difficult to maintain a reasonable home life.').

3. Surgeons struggling with personal protective equipment (PPE).

While working during the COVID-19 pandemic, surgeons faced many problems related to PPE, including a lack of PPE and discomfort associated with wearing PPE.

Selected comments mentioned a lack of PPE and that surgeons struggled with and 'ability to deliver care due to lack of PPE'. This lack might make surgeons feel unsafe in their work, causing anxiety about their safety. Other surgeons struggled PPE causing communication difficulties (eg, 'Carrying out emergency surgeries with less 
familiar teams and adapting the ways of communication during the case due to PPE'). Surgeons also spent significantly more time donning and doffing PPE as well as performing infection control at work and on returning home (eg, 'on-COVID wards means spending lots of time donning/doffing PPE rather than seeing patients'). Worry, annoyance and time pressure regarding these elements illustrated surgeon struggles with PPE.

\section{Theme two: challenges to professional life and development}

This theme describes how COVID-19 pandemic has affected surgeons' performance at work and their experience of professional development.

\section{Impact on surgeons' performance.}

Some surgeons commented about difficulties in planning and making decisions (eg, 'It is intellectually tiring to make decisions'). Many also mentioned about how COVID-19 affects their performance by making them less productive and slower at work 'Less productive and innovative'; 'Work is mundane and slow'. In addition to difficulties in planning and lack of productivity, several comments relate to surgeons feeling tired and even exhausted during the period of COVID-19 crisis (eg, 'Tired, often struggle to find motivation').

\section{Impact on surgeons' development.}

A number of comments express how COVID-19 outbreak affects training (eg, 'Training severely limited' and 'Zero access to any training, either in theatre or clinic'). Apart from the lack of training, many surgeons expressed their concern about achieving an Annual Review of Competence Progression (ARCP) 'worry about achieving competency for ARCP').

Theme three: management of change and loss in personal lives This theme describes the effects of the COVID-19 pandemic on surgeons' lives outside work.

\section{Childcare issues.}

Most remarks about how COVID-19 crisis affects surgeons' lives are about how surgeons struggle with childcare issues (eg, 'Difficult having teenagers at home with school being closed' and 'struggled with childcare'.

\section{Family life and relationships.}

Several participants expressed how, in order to avoid transmission of COVID-19, their communication with their family was affected: 'Not being able to live with my wife as having to live near hospital in Travelodgemakes communication harder' and 'Not being able to travel and support elderly parents abroad in case they run into problems'.

3. Cancellation of life pans such as weddings and honeymoons.

Personal challenges were encountered regarding life plan changes, such as having to cancel honeymoons or weddings, causing surgeons to feel frustrated about a lack of agency or disappointed by unmet expectations. These were illustrated by mentions of life plan changes: 'Postponement of our wedding', 'Wedding, honeymoon and annual leave cancelled'.

\section{Reduce leisure opportunity.}

In addition, reduced leisure opportunities were mentioned (eg, 'travel. The pub is shut and I can't go on holiday' and 'Home life-still seem to be working stressful days but little to no balance with sports or leisure, so life seems fairly imbalanced'. By contrast, one comment mentioned the increased leisure opportunities: 'Less work, more family time, and more golf!'

\section{Poor sleep.}

Eight statements expressed participants' struggles with poor sleep. These included quality of sleep and lack of sleep (eg, 'Strange dreams!' and 'struggling to sleep sometimes'.

\section{Theme four: emotional and psychological impact}

This theme describes psychological and emotional effects during the COVID-19 pandemic.

\section{Fear and anxiety.}

Surgeons' fear and anxiety about the disease and bringing the virus home was raised numerous times. Many comments describe feeling of fear, for example, 'fear of bringing the virus home and infecting my family and my mother in law with lung cancer' and feeling 'Anxious about bringing the virus home'.

Concern about patients and work. This refers to surgeons' concerns about being responsible for their patients and work: 'I am concerned about the impact on noncancer patients, particularly neuropathic patients' and 'Feeling pressure to find patients with cancer and enable them to have the care they need with the current limited system'.

Anticipatory anxiety and uncertainty. This category relates to many comments that expressed surgeons' concerns about the future and uncertainty (eg, 'feeling of anticipation of things getting worse' and 'What will my job look like in the coming months/years and how will I be able to arrange family commitments/childcare around this'.

2. Loss of motivation.

Feeling bored and having decreased motivation levels at work is considered one of the emotional impacts of the COVID-19 pandemic: 'Decreased motivation at work' and 'Tired, often struggling to find motivation'.

\section{Low mood.}

Participants reported having low moods during COVID-19 crisis, including feeling irritable (eg, 'very much, started having irritability (sic)' and 'anger'. Participants also expressed feeling unsettled ('Feel more unsettled than usual') or even becoming more emotional ('Makes me a lot more emotional than I have ever been') or feeling hopeless and annoyed: 'Feeling hopeless'). One participant expressed a feeling of giving up and feeling unable to adapt: 'I try to cope. Sometimes I feel that I am gonna give up'.

From the opposite side, some surgeons mentioned they are adapting to this current situation: 'New way of 
life requiring rapid adaptation' and 'adapting to work and out of work life'.

\section{Stress and burnout.}

Stress and burnout were also considered some of the key emotional and psychological effects of the COVID-19 pandemic. Several comments mentioned 'I feel burned out' and 'Very stressed at the start of the pandemic over catching COVID-19'. However, one remark shows the opposite and mentioned this time during COVID-19 crisis is less stressful: 'I don't feel more stressed. Maybe even less'.

\section{DISCUSSION}

This study aimed to understand the professional and personal effects of the COVID-19 pandemic on practicing surgeons. It found that 8 out of 10 surgeons reported that they were negatively affected by COVID-19 outbreak, with many respondents highlighting the increased challenges of their work environment. Respondents also emphasised the need to manage change in their professional and personal lives. Finally, the results of this study underscore the substantial emotional and psychological effects of COVID-19 pandemic on surgeons' mental health, particularly in relation to fear and anxiety, loss of motivation, low mood, stress and burnout. These findings are important because the demands of the surgical aspects of healthcare are different from other medical specialities, therefore, they call for different approaches to support surgeons.

The qualitative analysis of surgeons' comments revealed the changing and challenging work environments resulting from COVID-19 pandemic, including surgeons' worries about the delay and cancellation of planned operations. The consistency of the working in hospital settings has drastically changed due to the pandemic; COVID-19 cases have been prioritised because of their urgency. This is bound to disturb the standard operating procedures in surgical cases and cause complications and untimely responses to patients, while even inducing unwanted stress in surgeons. This is in accordance with Søreide $e t$ $a l,{ }^{22}$ who found that the COVID-19 emergency can affect the long-term delivery of surgical services and lead to cancellations and delays. Similarly, Chadi et $a t^{23}$ found that almost $27 \%$ of respondents mentioned interruptions in the delivery of surgical services.

Limited PPE was also one of the major challenges surgeons reported facing during the pandemic. We found that shortages of PPE negatively impacted surgeons, making them fearful and anxious about their own safety and the safety of their patients and their families. This result is similar to findings reported in a study by Jessop et $a l,{ }^{13}$ which found that the lack of PPE combined with changing and unclear structures in the work environment resulted in confusion and anxiety for healthcare staff. In the hospital setting, administrators and healthcare teams should have already set up standard guidelines to follow for effective operations that include adequate precautions in response to potential pandemics, which are vital since surgical operations are highly invasive and pose greater risks for both patients and surgeons. ${ }^{24}$ If these guidelines are properly followed, surgeries are still expected to proceed, even in the midst of the pandemic, and minimal cancellations due to risk of infection will be expected, all of which will improve the working conditions for surgical teams. Consideration must also be given to surgeons who have high-risk family members, such as elderly relatives, children and even other healthcare workers, all of which may contribute to higher levels of anxiety for surgeons themselves. ${ }^{25}$

The second and third themes to emerge from this study relate to the challenges to surgeons' personal and professional lives and their development during the COVID-19 pandemic. From the perspective of training practitioners, adjustments to educational programmes in response to this unexpected interruption should be put into place to minimise the disruption of the continuity of learning. In light of this, a lack of training is one of the main aspects of this theme that affects surgeons negatively. This result is consistent with a previous study of surgeons in Italy, which found that the COVID-19 pandemic had a negative impact on their educational programme, which includes a training component. ${ }^{26}$ Furthermore, $80 \%$ of surgeons who participated in a survey in India reported that their learning had been adversely affected by the COVID-19 pandemic. ${ }^{27}$ Hence, training hospitals should take this into consideration and reassure trainees. This study has implications for future research to formulate clear guidelines that compensate for cancelled training courses and lost time, which might help mitigate the stress currently experienced by surgeons and inform them how to reschedule training. This study also recommends virtual and simulation-based training during a pandemic. While surgeon training courses may require physical attendance due to their complexity, trainers should consider alternative methods (webinars and immersive technologies) to facilitate surgical training. Such adaptations have been universally tested as remote learning methods and have been deemed increasingly effective, even in the niche area of surgery. ${ }^{28}$ In lieu of lost opportunities to experience in-hospital training, virtual programmes must be supplemented by in-hospital simulated skill training.

Besides the training setting, personal and psychosocial needs are also expected to be part of surgeons' coping strategies. Proper scheduling of hospital duties will allow surgeons to have quality time for their families and themselves, allowing recovery from the demands of work. ${ }^{29}$ Knowing the adaptations currently practised by surgeons that have been shown to be effective should be discussed further so that these coping mechanisms can be disseminated throughout the surgical community and help administrators and managers foster better adaptations within their institutions.

The fourth theme that emerged from this study relates to the management of change and loss in the respondents' personal lives and to the emotional and psychological impacts surgeons are experiencing during the 
COVID-19 pandemic. The current findings are consistent with those of $\mathrm{Li}$ et $a l^{6}{ }^{6}$ who found that COVID-19 pandemic negatively affected mental health because of the special precautions required that may affect effective communication, personal contact and overall interaction, all of which are vital components of healthy psychosocial well-being. The personal and psychosocial effects of working through the pandemic on surgeons must not be disregarded as they can affect their quality of work and the success of their interventions. Moreover, there is growing evidence to show that job strain, burnout and low well-being are associated with poor patient safety and medical errors. ${ }^{30}$ In addition, such impacts may create long-term complications in surgeons' well-being that can affect them even after the pandemic subsides. A study by Lu $e t a l^{31}$ reported that frontline medical staff suffered more from fear, anxiety and depression than they did before the COVID-19 pandemic. Focusing on frontline healthcare professionals, a study by Wang $e t a l^{7}$ discovered many suffering from acute stress disorder, with a high prevalence of anxiety and depression. Evidently, the additional challenges of working in a clinical setting have already contributed to high levels of mental distress in healthcare workers. Three recent studies have shown that healthcare staff working with patients with COVID-19 are experiencing very high levels of anxiety and depression. ${ }^{32-34}$ Furthermore, the current findings also support $\mathrm{Wu}$ et $a l \mathrm{~s}^{35}$ results that have shown that COVID-19 pandemic has had a significant impact on health workers' worries about infection and their families, as well as on their sleep quality. With deteriorating mental health, it is likely that the effectiveness of each healthcare worker is compromised and this may impact on their well-being for an extended period of time.

The current study has a number of limitations, including the fact that two open-ended questions may not provide sufficient insight into surgeon mental health, limiting descriptions to one aspect of how COVID-19 pandemic affected them (eg, how working during the pandemic affected their families). We could also have conducted semistructured interviews to gain a deeper understanding of pandemic-related problems. However, we felt it unreasonable to ask surgeons to participate in such detailed interviews during these stressful times, when surgeons are already under immense pressure. Nevertheless, it is important to note that the thematic analysis provided a broad range of responses, yielding a rich dataset.

Another limitation relates to the fact that we were not able to monitor our response rate, and as such, it is not possible to know whether our sample reflected the wider population of UK surgeons from which it was recruited. In addition, this study required surgeons to self-report their well-being and the challenges they had experienced. As surgeons are reluctant to share emotional distress and seek support, ${ }^{16}$ this might have caused participants to avoid providing in-depth information about their COVID-19 pandemic struggles. If feasible, future studies ought to include other more objective evaluations of mental health (eg, clinical interviews) and investigate the reasons why surgeons are less likely to seek support and to discuss issues relating to their own mental health.

The aforementioned limitations notwithstanding, the current study also has several strengths. First, the results may have broader implications for fully understanding and being aware of the psychological and occupational effects of the COVID-19 pandemic on UK surgeons. The study findings may encourage other researchers to investigate the psychosocial effects of the pandemic on the working practices of surgeons and explore resolutions that would improve their working conditions. Furthermore, this study encompasses surgeons from different specialties, regions and grades, which provided a broad overview of how surgeons deal with difficulties, as well as an understanding of their fears and emotional and psychological problems during the COVID-19 pandemic. In addition, it was clear that each subspecialty and demographic group had its own challenges that can be brought to light, especially ones usually missed by other studies. In addition, this study used thematic analysis, which is considered a flexible method to identify themes based on participants' answers.

In conclusion, this study found that over $80 \%$ of surgeons who responded reported being negatively affected by the COVID-19 pandemic, with many respondents highlighting increased challenges in their work environments. Respondents also emphasised a need to manage change in their professional and personal lives, highlighting the substantial emotional and psychological effects of the COVID-19 pandemic on surgeon mental health (eg, fear and anxiety, loss of motivation, low mood, stress and burnout). There is an urgent need for workplace support and mental health intervention to help surgeons cope with the difficulties they face during the ongoing COVID-19 pandemic.

Correction notice This article has been corrected since it was published. Affiliation for Chandra Shekhar Biyani has been corrected.

Twitter Tmam Abdulaziz Al-Ghunaim @ag_Tmam

Acknowledgements The authors would like to thank all participants' surgeons for their support. We also acknowledge Joanne Johnson, Surgical Training Programme Manager, for her help to collect data.

Contributors TAAG, JJ, CSB and DOC were responsible for designing and implementing the research, analysing the results and the writing of the manuscript.

Funding The authors have not declared a specific grant for this research from any funding agency in the public, commercial or not-for-profit sectors.

Competing interests None declared.

Patient consent for publication Not required.

Ethics approval This study received ethical approval from the School of Psychology Research Ethics Committee at the University of Leeds on 4 May 2020 (Ethics Reference No: PSYC-34).

Provenance and peer review Not commissioned; externally peer reviewed.

Data availability statement All data relevant to the study are included in the article or uploaded as supplementary information.

Supplemental material This content has been supplied by the author(s). It has not been vetted by BMJ Publishing Group Limited (BMJ) and may not have been peer-reviewed. Any opinions or recommendations discussed are solely those of the author(s) and are not endorsed by BMJ. BMJ disclaims all liability and 
responsibility arising from any reliance placed on the content. Where the content includes any translated material, BMJ does not warrant the accuracy and reliability of the translations (including but not limited to local regulations, clinical guidelines, terminology, drug names and drug dosages), and is not responsible for any error and/or omissions arising from translation and adaptation or otherwise.

Open access This is an open access article distributed in accordance with the Creative Commons Attribution Non Commercial (CC BY-NC 4.0) license, which permits others to distribute, remix, adapt, build upon this work non-commercially, and license their derivative works on different terms, provided the original work is properly cited, appropriate credit is given, any changes made indicated, and the use is non-commercial. See: http://creativecommons.org/licenses/by-nc/4.0/.

\section{ORCID iDs}

Tmam Abdulaziz Al-Ghunaim http://orcid.org/0000-0001-8347-5148

Daryl 0'Connor http://orcid.org/0000-0003-4117-4093

\section{REFERENCES}

1 Yang $\mathrm{Y}$, Zhang $\mathrm{H}$, Chen $\mathrm{X}$. Coronavirus pandemic and tourism: dynamic stochastic General equilibrium modeling of infectious disease outbreak. Ann Tour Res 2020;83:102913.

2 World Health Organization. 2020 novel coronavirus (2019-nCoV) (COVID-19) pandemic, 2020. Available: https://www.who.int/docs/ default-source/coronaviruse/situation-

3 O'Connor DB, Aggleton JP, Chakrabarti B, et al. Research priorities for the COVID-19 pandemic and beyond: a call to action for psychological science. Br J Psychol 2020;111:e12468:603-29.

4 O'Connor RC, Wetherall K, Cleare S, et al. Mental health and wellbeing during the COVID-19 pandemic: longitudinal analyses of adults in the UK COVID-19 Mental Health \& Wellbeing study. Br J Psychiatry 2020;57:1-8.

5 Bao Y, Sun Y, Meng S, et al. 2019-nCoV epidemic: address mental health care to empower Society. The Lancet 2020;395:e37-8.

6 Li S, Wang Y, Xue J, et al. The impact of COVID-19 epidemic declaration on psychological consequences: a study on active Weibo users. Int J Environ Res Public Health 2020;17:2032.

7 Wang Y, Duan Z, Peng K, et al. Acute stress disorder among frontline health professionals during the COVID-19 outbreak: a structural equation modelling investigation. Psychosom Med 2020. doi:10.1097/PSY.0000000000000851. [Epub ahead of print: 17 Aug 2020].

8 Calhoun KE, Yale LA, Whipple ME, et al. The impact of COVID-19 on medical student surgical education: implementing extreme pandemic response measures in a widely distributed surgical clerkship experience. Am J Surg 2020;220:44-7.

9 Hunter E, Price DA, Murphy E, et al. First experience of COVID-19 screening of health-care workers in England. The Lancet 2020;395:e77-8.

10 lacobucci G. Covid-19: all non-urgent elective surgery is suspended for at least three months in England. BMJ 2020;368:m1106.

11 Willan J, King AJ, Jeffery K, et al. Challenges for NHS hospitals during covid-19 epidemic. BMJ 2020;368:m1117.

12 Choudhury T, Debski M, Wiper A, et al. Covid-19 pandemic: looking after the mental health of our healthcare workers. Occup Environ Med 2020;62:e373-6.

13 Jessop ZM, Dobbs TD, Ali SR, et al. Personal protective equipment for surgeons during COVID-19 pandemic: systematic review of availability, usage and rationing. Br J Surg 2020;107:1262-80.

14 Greenberg N, Docherty M, Gnanapragasam S, et al. Managing mental health challenges faced by healthcare workers during covid-19 pandemic. BMJ2020;368:m1211.
15 Kisely S, Warren N, McMahon L. Occurrence, prevention, and management of the psychological effects of emerging virus outbreaks on healthcare workers: rapid review and meta-analysis. BMJ 2020;369:m1642.

16 Gerada C, Jones R. Surgeons and mental illness: a hidden problem? BMJ 2014;348:g2764.

17 Upton D, Mason V, Doran B, et al. The experience of burnout across different surgical specialties in the United Kingdom: a cross-sectional survey. Surgery 2012;151:493-501.

18 Statista. Number of specialist surgeons employed in the United Kingdom (UK) from 2000 to 2019, 2019. Available: https://www. statista.com/statistics/473172/specialist-surgeon-employment-inthe-united-kingdom-uk/ [Accessed 13 Feb 2021].

19 Malterud K, Siersma VD, Guassora AD. Sample size in qualitative interview studies. Qual Health Res 2016;26:1753-60.

20 Braun V, Clarke V. Using thematic analysis in psychology. Qual Res Psychol 2006;3:77-101.

21 Taylor PJ, Awenat Y, Gooding P, et al. The subjective experience of participation in schizophrenia research: a practical and ethical issue. J Nerv Ment Dis 2010;198:343-8.

22 Søreide K, Hallet J, Matthews JB, et al. Immediate and long-term impact of the COVID-19 pandemic on delivery of surgical services. Br J Surg 2020;107:1250-61.

23 Chadi SA, Guidolin K, Caycedo-Marulanda A, et al. Current evidence for minimally invasive surgery during the COVID-19 pandemic and risk mitigation strategies: a narrative review. Ann Surg 2020;272:e118-24.

24 Hojaij FC, Chinelatto LA, Boog GHP, et al. Surgical practice in the current COVID-19 pandemic: a rapid systematic review. Clinics2020;75:e1923.

25 Xu J, Xu Q-H, Wang C-M, et al. Psychological status of surgical staff during the COVID-19 outbreak. Psychiatry Res 2020;288:112955.

26 Pertile D, Gallo G, Barra F, et al. The impact of COVID-19 pandemic on surgical residency programmes in Italy: a nationwide analysis on behalf of the Italian Polyspecialistic young surgeons Society (SPIGC). Updates Surg 2020;72:269-80.

27 Mishra D, Nair AG, Gandhi RA. The impact of COVID-19 related lockdown on ophthalmology training programs in India - Outcomes of a survey. Indian J Ophthalmol 2020;68:999-1004.

28 McKechnie T, Levin M, Zhou K, et al. Virtual surgical training during COVID-19: operating room simulation platforms accessible from home. Ann Surg 2020;272:e153-4.

29 George I, Salna M, Kobsa S, et al. The rapid transformation of cardiac surgery practice in the coronavirus disease 2019 (COVID-19) pandemic: insights and clinical strategies from a centre at the epicentre. Eur J Cardiothorac Surg 2020;58:667-75.

30 O'Connor DB, Hall LH, Johnson J. The triple Challenge: Connecting health care workers wellbeing, patient safety and organizational change. In: van der Doef M, Panagopoulou E, Leiter M, eds. Health care workers wellbeing, patient safety and organizational change. Springer, 2020.

31 Lu W, Wang H, Lin Y, et al. Psychological status of medical workforce during the COVID-19 pandemic: a cross-sectional study. Psychiatry Res 2020;288:112936.

32 Huang JZ, Han MF, Luo TD, et al. [Mental health survey of medical staff in a tertiary infectious disease hospital for COVID-19]. Zhonghua Lao Dong Wei Sheng Zhi Ye Bing Za Zhi 2020;38:192-5.

33 Lai J, Ma S, Wang Y, et al. Factors associated with mental health outcomes among health care workers exposed to coronavirus disease 2019. JAMA Netw Open 2020;3:e203976.

34 Chen Q, Liang M, Li Y, et al. Mental health care for medical staff in China during the COVID-19 outbreak. The Lancet Psychiatry 2020;7:e15-16.

35 Wu W, Zhang Y, Wang P, et al. Psychological stress of medical staffs during outbreak of COVID-19 and adjustment strategy. J Med Virol 2020;92:1962-70. 